\title{
Pengaruh Kualitas Pelayanan dan Budaya Terhadap Daya Tarik dan Minat Berkunjung ke Wisata Percut
}

\section{The Influence of Service Quality and Culture on Attraction and Interest in Revisiting Percut Tourism}

\author{
Mery Lani Purba1*, Glory Simarmata2* \\ 1) Program Studi Manajemen ,Universitas Sari Mutiara Indonesia, Sumatera Utara \\ 2) Program Studi Manajemen, Universitas Sutomo, Sumatera Utara \\ *Coresponding Email: melanie_lavina@yahoo.com
}

\begin{abstract}
Abstrak
Penelitian ini bertujuan untuk mengetahui faktor-faktor determinan yang mempengaruhi minat kunjungan kembali wisatawan ke Wisata Bahari Percut Sei Tuan Deli Serdang dilihat kondisi kualitas pelayanan, budaya masyarakat dan pengaruhnya terhadap daya tarik wisata dan minat berkunjung kembali di daerah tersebut. Populasi penelitian ini ada wisatawan lokal maupun mancanegara yang pernah berkunjung ke wisata Bahari Percut Sei Tuan. Metode penelitian yang digunakan adalah penelitian kausal yaitu untuk melihat hubungan antar variabel dan faktor yang paling dominan mempengaruhi variabel dependen. Hasil penelitian ini adalah kualitas pelayanan dan budaya masyarakat berpengaruh positif dan signifikan terhadap daya tarik Wisata Bahari Percut Sei Tuan. Demikian juga daya tarik wisata berpengaruh positif dan signifikan terhadap minat berkunjung kembali ke tempat wisata Bahari Percut Sei Tuan.
\end{abstract}

Kata kunci: Kualitas Pelayanan, Budaya, Daya Tarik, Minat Berkunjungan

\section{Abstract}

This study aims to determine the determinant factors that influence the interest of tourist return visits to Bahari Percut Sei Tuan Deli Serdang Tourism as seen from the condition of service quality, community culture and its influence on tourism attraction and intention in revisiting the area. The population of this research is local and foreign tourists who have visited the tourism site. The research method used is causal research which is to see the relationship between variables and the most dominant factors affecting the dependent variable. The results of this study are service quality and community culture positive and significant effect on tourism attraction of Bahari Percut Sei Tuan Tourism. And also tourism attraction positive and significant effects on the interest in revisiting Bahari Percut Sei Tuan Tourism.

\section{Keywords: Service Quality, Culture, Tourism Attraction, Revisiting ntention}

How to Cite: Pertama, M.L.P. Kedua, G.S, P. (2018). Pengaruh Kualitas Pelayanan dan Budaya Terhadap Daya Tarik dan Minat Berkunjung ke Wisata Percut, Jurnal Konsep Bisnis dan Manajemen. 5(1) Nov, 2018 : 106-117 


\section{PENDAHULUAN}

Dunia pariwisata Indonesia saat ini sangat berpengaruh terhadap pertumbuhan ekonomi bangsa. Hal ini dilihat dari bertambahnya jumlah wisatawan yang datang dari waktu ke waktu baik domestik maupun mancanegara, umumnya mereka yang berwisata ke Indonesia sekedar berlibur atau berpetualang menikmati keindahan kekayaan alamnya dan budayanya yang sangat beragam. Ditingkat daerah sektor pariwisata diharapkan dapat membantu dalam menunjang pendapatan daerah, yang nantinya bisa digunakan untuk mengembangkan potensi daerah yang lain dan dapat meningkatkan pembangunan daerah yang lebih baik.

Wisata Bagan Percut Sei Tuan memiliki potensi daya tarik wisata yang baik dilihat dari kondisi alam yang masih alami yaitu kondisi laut dan hutan bakau yang ada. Wisata Bagan Percut Sei Tuan terletak di Desa Percut Kabupaten Deli Serdang dengan luas sebesar 190,79 km2 dengan jumlah penduduk sebanyak 405.570 orang.

Sebagian besar penduduk di wilayah ini bermata pencaharian di sektor pemanfaatan sumberdaya kelautan (marine resources base), seperti nelayan, petani ikan (budidaya tambak dan laut), Kemiskinan masyarakat nelayan (problem struktural), penambangan pasir, kayu mangrove dan lain-lain. Sebagian besar penduduk Desa Percut Sei Tuan memiliki tingkat pendidikan yang rendah. Mayorits merupakan tamatan Sekolah Dasar (SD) dan sejalan dengan tingkat tersebut, fasilitas pendidikan yang ada masih sangat terbatas.

Tempat ini juga merupakan persinggahan migrasi bangau dari Eropa ke Afrika pada bulan September sampai dengan Maret setiap tahunnya. Dalam melakukan migrasi ini burung bangau singgah di hutan bakau yang ada di Kecamatan Percut Sei Tuan. Namun hutan mangrove atau yang biasa dikenal dengan hutan bakau khususnya di Sumatera Utara dinilai dalam keadaan kritis karena terdapat kerusakan. Luas area hutan mangrove yang sebelunya 200.000 ha di tahun 1987 telah menyusut tajam menjadi 37.500 ha pada tahun 2001 disebabkan konversi kebun sawit, pertambakan dan pemukiman penduduk (Tribun, 2017). Memperbaiki kondisi kerusakan tersebut, diperlukan perubahan sikap dan persepsi. Tindakan ini perlu dilakukan, karena selain berfungsi menjaga daratan dari derusan ombak dan tempat hidup serta berbiaknya biota laut, kawasan hutan ini juga berpotensi dikembangkan sebagai wisata alam. 
Mery Lani Purba, Glori Simarmata, Pengaruh Kualitas Pelayanan dan Budaya terhadap Daya Tarik dan Minat Berkunjung ke Wisata Percut

Kondisi lingkungan pemukiman masyarakat pantai, khususnya nelayan masih belum tertata dengan baik dan terkesan kumuh. Dengan kondisi sosial ekonomi masyarakat yang relatif berada dalam tingkat kesejahteraan rendah, maka dalam jangka panjang tekanan terhadap sumberdaya pesisir akan semakin besar guna pemenuhan kebutuhan pokoknya.

Masyarakat nelayan akrab dengan ketidakpastian yang tinggi karena secara alamiah sumber daya perikanan bersifat invisible sehingga sulit untuk diprediksi. Sementara masyarakat agraris misalnya memiliki ciri sumberdaya yang lebih pasti dan visible sehingga relatif lebih mudah untuk diprediksi terkait dengan ekspetasi sosial ekonomi masyarakat. Dalam kondisi seperti ini maka tidak jarang ditemui karakteristik masyarakat nelayan yang keras, sebagian temparemental dan tidak jarang yang boros karena ada persepsi bahwa sumberdaya perikanan "tinggal diambil" di laut.

Untuk menjadi tempat wisata yang diminati maka selain kondisi alam yang indah perlu juga didukung dengan fasilitas dan pelayanan yang baik dari pengelola wisata dan juga masyarakat setempat. Saat ini jika berkunjung ke
Wisata Bagan Desa Percut Kecamatan Percut Sei Tuan terdapat beberapa restauran di atas laut. Restauran ini menyajikan kuliner berbahan dasar ikan laut tangkapan nelayan. Untuk menuju restauran ini pengunjung harus menggunakan sampan atau kapal motor. Biasanya pengunjung mengikuti tour hutan bakau dahulu sebelum beristirahat dan menikmati pemandangan laut dari restauran, Hanya saja dari hasil observasi penulis terlihat bahwa restauran tidak tertata dengan baik, dapur dan toilet yang kurang bersih dan juga pelayanan yang kurang ramah serta harga makanan yang mahal.

Mengetahui hal tersebut diatas penulis merasa tertarik untuk meneliti pengaruh kualitas pelayanan dan budaya masyarakat terhadap daya tarik wisata dan minat berkunjung kembali ke Wisata Bagan Percut Kecamatan Percut Sei Tuan.

Kualitas pelayanan menurut Kotler (2013) merupakan totalitas dari bentuk karakteristik barang dan jasa yang menunjukkan kemampuannya untuk memuaskan kebutuhan pelanggan, baik yang nampak jelas maupun yang tersembunyi. Bagi perusahaan yang bergerak di sektor jasa, pemberian pelayanan yang berkualitas pada 
pelanggan merupakan hal mutlak yang harus dilakukan apabila perusahaan ingin mencapai keberhasilan.

Untuk mengidentifikasi kualitas pelayanan peneliti menggunakan dimensi ServQual (Service Quality) (Tjiptono, 2012) yang dipakai untuk mengukur kualitas pelayanan, lima dimensi tersebut adalah: 1)Tangibles, merupakan bukti nyata dari kepedulian dan perhatian yang diberikan oleh penyedia jasa kepada konsumen. 2)Reliability atau keandalan, merupakan kemampuan perusahaan untuk melaksanakan jasa sesuai dengan apa yang telah dijanjikan secara tepat waktu. 3)Responsiveness atau daya tanggap, merupakan kemampuan perusahaan yang dilakukan oleh langsung karyawan untuk memberikan pelayanan dengan cepat dan tanggap, 4) Assurance atau jaminan, merupakan pengetahuan dan perilaku karyawan untuk membangun kepercayaan dan keyakinan pada diri konsumen dalam mengkonsumsi jasa yang ditawarkan, 5) Emphaty, merupakan kemampuan perusahaan yang dilakukan langsung oleh karyawan untuk memberikan perhatian kepada konsumen secara individu, termasuk juga kepekaan akan kebutuhan konsumen.
Budaya adalah suatu cara hidup yang berkembang dan dimiliki bersama oleh sebuah kelompok orang dan diwariskan dari generasi ke generasi. Budaya terbentuk dari banyak unsur yang rumit, termasuk sistem agama dan politik, adat istiadat, bahasa, perkakas, pakaian, bangunan, dan karya seni. Bahasa, sebagaimana juga budaya, merupakan bagian tak terpisahkan dari diri manusia sehingga banyak orang cenderung menganggapnya diwariskan secara genetis. Ketika seseorang berusaha berkomunikasi dengan orangorang yang berbeda budaya dan menyesuaikan perbedaanperbedaannya, membuktikan bahwa budaya itu dipelajari.

Berdasarkan wujudnya tersebut, budaya memiliki beberapa elemen atau komponen, menurut ahli antropologi Cateora, yaitu:

- Kebudayaan material

Kebudayaan material mengacu pada semua ciptaan masyarakat yang nyata, konkret. Termasuk dalam kebudayaan material ini adalah temuantemuan yang dihasilkan dari suatu penggalian arkeologi

- Kebudayaan nonmaterial Kebudayaan nonmaterial adalah ciptaan-ciptaan abstrak yang diwariskan dari generasi ke generasi, misalnya 
Mery Lani Purba, Glori Simarmata, Pengaruh Kualitas Pelayanan dan Budaya terhadap Daya Tarik dan Minat Berkunjung ke Wisata Percut

berupa dongeng, cerita rakyat, dan lagu atau tarian tradisional.

- Lembaga sosial

Lembaga sosial dan pendidikan memberikan peran yang banyak dalam kontek berhubungan dan berkomunikasi di alam masyarakat. Sistem sosial yang terbantuk dalam suatu Negara akan menjadi dasar dan konsep yang berlaku pada tatanan sosial masyarakat.

- Sistem kepercayaan

Bagaimana masyarakat mengembangkan dan membangun sistem kepercayaan atau keyakinan terhadap sesuatu, hal ini akan mempengaruhi sistem penilaian yang ada dalam masyarakat.

Estetika

Berhubungan dengan seni dan kesenian, musik, cerita, dongeng, hikayat, drama dan tari-tarian, yang berlaku dan berkembang dalam masyarakat.

Bahasa merupakan alat pengatar dalam berkomunikasi, bahasa untuk setiap wilayah, bagian dan Negara memiliki perbedaan yang sangat komplek. Jadi keunikan dan kekomplekan bahasa ini harus dipelajari dan dipahami agar komunikasi lebih baik dan efektif dengan memperoleh nilai empati dan simpati dari orang lain.

Daya tarik wisata merupakan salah satu unsur penting dalam dunia kepariwisataan. Di mana daya tarik wisata dapat menyukseskan program pemerintah dalam melestarikan adat dan budaya bangsa sebagai asset yang dapat dijual kepada wisatawan. Daya tarik wisata dapat berupa alam, budaya, tata hidup dan sebagainya yang memiliki daya tarik dan nilai jual untuk dikunjungi ataupun dinikmati oleh wisatawan. Dalam arti luas, apa saja yang mempunyai daya tarik wisata atau menarik wisatawan dapat disebut sebagai objek dan daya tarik wisata. Produk pariwisata meliputi keseluruhan pelayanan yang diperoleh, dirasakan, dimiliki dan dinikmati oleh wisatawan sejak ia meninggalkan rumah, tempat tinggal sampai ke daerah wisata yang dipilihnya hingga kembali ke tempat asalnya. Untuk dapat menjadi suatu daerah tujuan wisata yang baik maka kita harus mengembangkan tiga hal yaitu : 1. Something to see, adalah segala sesuatu yang menarik untuk dilihat. 2 . Something to buy, adalah segala sesuatu yang menarik atau mempunyai ciri khas tersendiri untuk dibeli; 3. Something to do, yaitu suatu aktivitas yang dapat dilakukan di tempat tersebut. Ketiga hal itu merupakan unsur-unsur yang kuat untuk suatu daerah tujuan wisata.

Menurut International Union of Official Travel Organization (IUOTO), 
pengunjung yaitu setiap orang yang datang ke suatu negara atau tempat tinggal lain dan biasanya dengan maksud apapun kecuali untuk melakukan pekerjaan yang menerima upah.Fa ktor yang mempengaruhi minat kunjungan adalah atraksi daerah, fasilitas dan aksesibilitas.

\section{METODE PENELITIAN}

Pendekatan penelitian yang digunakan dalam penelitian ini adalah pendekatan deskriptif dan dalam mendeskripsikan/menggambarkan masalah, peneliti menggunakan jenis penelitian kausal dengan tujuan untuk mengetahui faktor yang paling dominan yang mempengaruhi minat berkunjung kembali ke Wisata Bahari Percut Sei Tuan. Jumlah sampel dalam penelitian ini ada sebanyak 134 orang pengunjung yaitu wisatawan yang sebelumnya sudah pernah berwisata ke tempat ini minimal satu kali.

\section{HASIL DAN PEMBAHASAN}

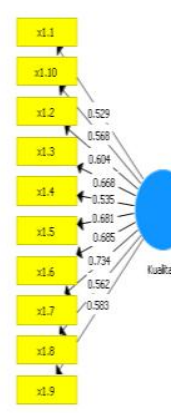

Gambar 1. Model

Tabel 1. Uji Pengaruh Langsung (Direct Effect)

\begin{tabular}{|l|c|c|c|c|c|}
\hline & $\begin{array}{l}\text { Original } \\
\text { Sample (0) }\end{array}$ & $\begin{array}{l}\text { Sample Mean } \\
(\mathrm{M})\end{array}$ & $\begin{array}{l}\text { Standard Error } \\
\text { (STERR) }\end{array}$ & $\begin{array}{l}\text { T Statistics } \\
\text { (|O/STERR|) }\end{array}$ & P Values \\
\hline Budaya -> Daya Tarik & 0,212 & 0,212 & 0,140 & 2,109 & 0,030 \\
\hline $\begin{array}{l}\text { Budaya Minat } \\
\text { Berkunjung }\end{array}$ & 0,147 & 0,167 & 0,111 & 1,319 & 0,188 \\
\hline $\begin{array}{l}\text { Daya Tarik -> Minat } \\
\text { Berkunjung }\end{array}$ & 0,775 & 0,784 & 0,040 & 19,512 & 0,000 \\
\hline $\begin{array}{l}\text { Kualitas -> Daya Tarik } \\
\text { Kualitas Minat } \\
\text { Berkunjung }\end{array}$ & 0,351 & 0,376 & 0,150 & 2,340 & 0,020 \\
\hline
\end{tabular}

Sumber: Data diolah dengan SmartPLS v.3.2.1 
Mery Lani Purba, Glori Simarmata, Pengaruh Kualitas Pelayanan dan Budaya terhadap Daya Tarik dan Minat Berkunjung ke Wisata Percut

H1: Kualitas pelayanan berpengaruh positif dan signifikan terhadap daya tarik Wisata Bagan Desa Percut Kecamatan Percut Sei Tuan.

Tabel 1 menunjukkan bahwa Kualitas Pelayanan memiliki nilai koefisien sebesar 0,272 , nilai $t$-statistics sebesar 2.308 dan tingkat signifikansi 0,021. Hal ini menjelaskan bahwa diferensiasi pelayanan berpengaruh positif dan signifikan terhadap daya Hasil koefisien pada Tabel 1 menunjukkan budaya masyarakat terhadap keunggulan bersaing memiliki nilai positif yaitu 0.212 , nilai $t$-statistics sebesar 2.109 dan tingkat signifikansi 0.030. Hal ini menjelaskan bahwa budaya masyarakat berpengaruh positif dan signifikan terhadap daya tarik wisata yang berarti semakin baiknya budaya masyarakat maka akan meningkatkan daya tari Wisata Bagan Desa Percut Kecamatan Percut Sei Tuan. Hasil Penelitian ini sesuai dengan penelitian Siew et al. (2007), Suyan (2009) yang menyatakan bahwa budaya berpengaruh terhadap daya tarik wisata.

H2: Kualitas pelayanan berpengaruh positif dan signifikan terhadap minat berkunjung ke Wisata Bagan Percut Kecamatan Percut Sei Tuan. tarik wisata. Hasil Penelitian ini sesuai dengan penelitian Basiony et al.(2014), Lu et al.(2015), Kuong et al. (2017), yang menyatakan bahwa Kualitas Pelayanan berpengaruh pada daya tarik wisata dan minat berkunjung.

\section{H3: Budaya masyarakat berpengaruh} positif dan signifikan terhadap daya tarik Wisata Bagan Desa Percut Kecamatan Percut Sei Tuan.

Hasil koefisien pada Tabel 1 menunjukkan kemitraan terhadap keunggulan bersaing memiliki nilai positif yaitu 0.272 , nilai $t$-statistics sebesar 2.308 dan tingkat signifikansi 0.021. Hal ini menjelaskan bahwa kualitas pelayanan berpengaruh positif dan signifikan terhadap minat berkunjung yang berarti semakin baiknya kualitas pelayanan tempat wisata maka akan dapat juga meningkatkan peranan keunggulan bersaing dengan universitas lain minat berkunjung wisatawan. Hal ini sejalan dengan penelitian Romiti and Sarti ( 2016), Shonk, David (2008).

H4: Budaya masyarakat erpengaruh positif dan signifikan terhadap minat berkunjung kembali ke Wisata Bagan Percut Kecamatan Percut Sei Tuan. 
Tabel 1 menunjukkan budaya masyarakat memiliki pengaruh positif yaitu bersaing memiliki nilai positif yaitu 0,147 nilai T-statistics Ssebesar 1,319 dan tingkat signifikansi 0.188 . Hal ini menjelaskan bahwa budaya masyarakat berpengaruh positif namun tidak signifikan terhadap minat berkunjung wisatawan. Hasil ini sejalan dengan penelitian Romiti and Sarti ( 2016), Shonk, David (2008) yabf menyatakan bahwa budaya dapat menjadi faktor yang meningkatkan minat berkunjung wisatawan.

\section{H5: Daya tarik wisata berpengaruh positif dan signifikan terhadap minat berkunjung kembali ke Wisata Bagan Percut Kecamatan Percut Sei Tuan.}

Tabel 1 menunjukkan daya tarik wisatawan terhadap minat berkunjung memiliki nilai positif yaitu 0,775 , nilai $T$ statistics sebesar 19,512 dan tingkat signifikansi 0.000 . Hal ini menjelaskan bahwa daya tarik wisata berpengaruh positif dan signifikan minat berkunjung wisatawan yang berarti semakin tinggi daya tarik wisata suatu tempat maka minat berkunjung kembali juga akan semakin tinggi. Hasil ini sejalan dengan penelitian Cesar et al. (2015), Geofrey(20 17). Nowacki (2010) tentang daya tarik wisata yang dapat meningkatkan minat $\mathrm{b}$ erkunjung kembali.

\section{Uji Pengaruh Tidak Langsung (Indirect Effect)}

Hasil uji pengaruh tidak langsung (indirect effect) variabel laten yang dianalisis dapat dilihat pada Tabel 2.

Tabel 2. Uji Pengaruh Tidak Langsung (Indirect Effect)

\begin{tabular}{|c|r|r|r|r|r|}
\hline & $\begin{array}{c}\text { Original } \\
\text { Sample (O) }\end{array}$ & $\begin{array}{c}\text { Sample Mean } \\
\text { (M) }\end{array}$ & $\begin{array}{c}\text { Standard Error } \\
\text { (STERR) }\end{array}$ & $\begin{array}{c}\text { T Statistics } \\
\text { (|O/STERR|) }\end{array}$ & P Values \\
\hline $\begin{array}{c}\text { Budaya -> Daya Tarik -> } \\
\text { Minat Berkunjung }\end{array}$ & 0,147 & 0,167 & 0,111 & 1,319 & 0,188 \\
\hline $\begin{array}{c}\text { Kualitas -> Daya Tarik -> } \\
\text { Minat Berkunjung }\end{array}$ & 0,272 & 0,294 & 0,118 & 2,308 & 0,021 \\
\hline
\end{tabular}

Sumber: Data diolah dengan SmartPLS v.3.2.1

Tabel 2 menunjukkan bahwa Kualitas pelayanan terhadap minat berkunjung memiliki pengaruh langsung positif dan signifikan dengan nilai koefisien sebesar 0,272, tingkat signifikansi p-value sebesar 0,021. Nilai T-statistics pengaruh tidak langsung ini sebesar 2,308 lebih besardari nilai yang disarankan yaitu 1.96. Hal ini menjelaskan bahwa kualitas pelayanan memiliki pengaruh tidak langsung atau melalui variabel perantara/intervening yang positif dan signifikan terhadap minat berkunjung ke tempat wisata.

Budaya masyarakat terhadap minat berkunjung memiliki pengaruh 
Mery Lani Purba, Glori Simarmata, Pengaruh Kualitas Pelayanan dan Budaya terhadap Daya Tarik dan Minat Berkunjung ke Wisata Percut

tidak langsung positif dengan nilai kondisi tempat wisata yang ada masih koefisien sebesar 0,147, tingkat signifikansi p-value sebesar 0,188. Nilai T-statistics pengaruh tidak langsung ini sebesar 1,319 lebih kecil dari nilai yang disarankan yaitu 1.96. Hal ini menjelaskan bahwa kbudaya masyarakat memiliki pengaruh tidak langsung atau melalui variabel perantara/intervening yang positif namun tidak signifikan terhadap minat berkunjung kembali ke tempat wisata.

Berdasarkan hasil pengolahan data dan analisis, maka pada bagian ini akan dibahas hasil perhitungan yang akan dilakukan. Penelitian ini bertujuan untuk mengetahui pengaruh kualitas pelayanan dan budaya masyarakat terhadap daya tarik wisata dan minat berkunjung kembali ke Wisata Bagan Percut Kecamatan Percut Sei Tuan.

\section{Kualitas Pelayanan Terhadap Daya tarik Wisata Bagan Percut Kecamatan Percut Sei Tuan}

Hasil analisis data menunjukkan bahwa kualitas pelayanan memiliki nilai koefisien sebesar 0,272, nilai t-statistics sebesar 2.308 dan tingkat signifikansi 0,021. Hal ini menjelaskan bahwa diferensiasi pelayanan berpengaruh positif dan signifikan terhadap daya tarik wisata. Dari data yang diperoleh bahwa keindahan alam Desa Percut dan kurang terkelola dengan baik dan juga kebersihannya masih perlu ditingkatkan. Namun demikian makannan yang disajikan cukup enak walaupun terkadang pengunjung kurang merasa nyaman dan aman ketika melewati sungai karena kondisi perahu yang sudah sangat tua. Di tempat ini juga terdapat tempat untuk mencari informasi namun tempat tersebut harus lebih di perhatikan dan petugas juga harus selalu siaga. Sangat jarang kita melihat petugas petugas wisata yang memperhatikan kenyamanan pengunjung.

\section{Pengaruh Budaya Masyarakat Terhadap Daya Tarik Wisata Desa Percut Sei Tuan}

Hasil menunjukkan bahwa budaya masyarakat terhadap daya tarik wisata memiliki nilai positif yaitu 0.212 , nilai tstatistics sebesar 2.109 dan tingkat signifikansi 0.030 . Hal ini menjelaskan bahwa budaya masyarakat berpengaruh positif dan signifikan terhadap daya tarik wisata yang berarti semakin baiknya budaya masyarakat maka akan meningkatkan daya tarik wisata di Desa Percut Sei Tuan.

Secara umum dilihat bahwa rumah-rumah penduduk belum tertata dengan baik dan terlihat kumuh. Dalam 
melaksanakan pekerjaan sebagai nelayan juga belum menggunakan teknologi baru terlihat dari perahu dan jaring yang dipakai dalam menangkap ikan. Ikan yang dijual di tempat pelelangan masih segar karena baru saja ditangkap dari laut. Masyarakat dapat berkomunikasi dengan baik terhadap pengunjung namun terlihat bahwa hanya penjual dan nelayan saja yang berusaha menjalin komunikasi dengan pengunjung. Sedangkan masyarakat setempat terlihat kurang antusias menunjukkan keramahan budaya setempat.

\section{a. Pengaruh Kualitas Pelayanan Terhadap Minat Berkunjung Wisata Desa Percut Sei Tuan}

Hasil koefisien menunjukkan kualitas pelayanan terhadap minat berkunjung memiliki nilai positif yaitu 0.272, nilai t-statistics sebesar 2.308 dan tingkat signifikansi 0.021. Hal ini menjelaskan bahwa kualitas pelayanan berpengaruh positif dan signifikan terhadap minat berkunjung. Artinya semakin baiknya kualitas pelayanan tempat wisata maka akan dapat juga meningkatkan minat berkunjung wisatawan.

Kualitas pelayanan yang baik akan memberikan makna positif bagi pengunjung dan memberikan image positif. Kualitas pelayanan dapat menjadi faktor penentu wisatawan yang ingin berkunjung ke suatu tempat wisata. Kualitas pelayanan yang terdiri dari kondisi tempat wisata, keramahan, empati, tanggung jawab dan kepercayaan pada tempat wisata akan menarik wisatawan untuk berkunjung kembali ke tempat tersebut.

\section{b. Pengaruh Budaya Masyarakat terhadap Minat Berkunjung ke Wisata Bagan Desa Percut Sei Tuan}

Hasil analisis data menunjukkan bahwa menunjukkan budaya masyarakat memiliki pengaruh positif yaitu bersaing memiliki nilai positif yaitu 0,147 nilai T-statistics sebesar 1,319 dan tingkat signifikansi 0.188 . Hal ini menjelaskan bahwa budaya masyarakat berpengaruh positif namun tidak signifikan terhadap minat berkunjung wisatawan.

Dari observasi yang dilihat bahwa kondisi rumah penduduk dan keramahan masyarakat setempat serta konsisi social masyarakat setempat berpengaruh terhadap minat berkunjung wisatawan. Akan tetapi faktor ini bukanlah faktor dominan karena wisatawan lebih mengedepankan faktor keindahan alam dan sajian makanan yang enak dan segar yang mereka dapatkan dari tempat ini. 
Pengaruh Daya Tarik Wisata terhadap

Minat Berkunjung ke Wisata Bagan Desa

Percut Kecamatan Percut Sei Tuan

Hasil analisis data menunjukkan menunjukkan daya tarik wisatawan terhadap minat berkunjung memiliki nilai positif yaitu 0,775 , nilai T-statistics sebesar 19,512 dan tingkat signifikansi 0.000. Hal ini menjelaskan bahwa daya tarik wisata berpengaruh positif dan signifikan minat berkunjung wisatawan yang berarti semakin tinggi daya tarik wisata suatu tempat maka minat berkunjung kembali juga akan semakin tinggi. Pengunjung yang datang ke Desa Percut ini semata-mata karena ingin menikmati keindahan alam yang ada dengan harga yang cukup terjangkau dan makan yang didajikan merupakan ikan segar yang langsung diolah dari tangkapan laut. Selain itu pengunjung juga dapat menikmati hiburan denngan adanya live music keyboard dan penyanyi yang di ada di beberapa restoran.

\section{SIMPULAN}

Dari hasil penelitian dapat disimpulkan bahwa Kualitas pelayanan dan budaya masyarakat, berpengaruh positif dan signifikan terhadap daya tarik Wisata Bahari Percut Sei Tuan. Demikian juga daya tarik wisata berpengaruh positif dan signifikan terhadap minat berkunjung kembali ke tempat wisata Percut Sei Tuan.

Nilai-nilai pembentuk kualitas pelayanan yang baik seperti tangibles, realibility, responsiveness, emphaty, assurance di Wisata Percut Sei Tuan belum mencapai nilai yang diharapkan sehingga perlu ditingkatkan di masa mendatang. Demikian juga nilai budaya masyarakat seperti kondisi lingkungan, komunikasi, estetika, kepercayaan, dan cara hidup masyarakat di Desa Percut Kecamatan Percut Sei Tuan masih perlu ditingkatkan untuk dapat meningkatkan lagi daya tarik wisata.

\section{UCAPAN TERIMA KASIH}

Kami ucapkan terimakasih kepada Direktorat Riset dan Pengabdian Masyarakat Direktorat Jenderal Penguatan Riset dan Pengembangan Kemenristekdikti yang telah mendanai Penelitian Dosen Pemula ini.

\section{DAFTAR PUSTAKA}

Antari, Ni Luh Sili. (2013). Peran Industri Pariwisata Terhadap Penerimaan Pendapatan Asli Daerah Kabupaten Gianyar. Jurnal Perhotelan dan Pariwisata, Volume 3, No. 1

Badan Pusat Statistik Kabupaten Deli Serdang, Katalog: 1102001.1212260, Kecamatan Percut Sei Tuan dalam angka 2016

Basiony, Elazim, A, Ghada A and El Sayed, A.S, (2014), Evaluating Tourism Service Quality Provided to the European 
Tourist|Applied on the British tourist, Munich Personal RePEc Archive, pg 167174

César, Luis, Herrero-Prieto and Mafalda GómezVega, (2015), Cultural resources as a factor in cultural tourism attraction: Technical Efficiency Estimation Of Regional Destinations In Spain , Tourism Economics Vol 23, Issue 2, pp. 260 - 280

Carol, Lu, Berchoux, C, Michael W. Marek, Brendan Chen, (2015) "Service quality and customer satisfaction: qualitative research implications for luxury hotels", International Journal of Culture, Tourism and Hospitality Research, Vol. 9 Issue: 2, pp.168-182

Geoffrey, Wall, 2017, Ethnic and Minority Cultures as Tourist Attractions, Journal of Tourism Futures, Vol. 3 Issue: 2, pp.196197, International Union of Official Travel Organization (IUOTO)

Hadiwijoyo, S.S. (2012), Perencanaan Pariwisata Perdesaan Berbasis Masyarakat: Sebuah Pendekatan Konsep, Penerbit Graha Ilmu, Yogyakarta

Koentjaraningrat. (2015). Pengantar Ilmu Antropologi. Cetakan : I Jakarta: Rineka Cipta

Kastolani, W., (2012), Strategi Konservasi Wilayah Pesisir yang Berkelanjutan, Naskah Pidato Pengukuhan Guru Besar / Professor dalam Bidang Ilmu Geografi Lingkungan, 17 Juli, Fakultas Pendidikan dan Ilmu Pengetahuan Sosial, Bandung: Universitas Pendidikan Indonesia

Kotler, P dan Keller, L, K, (2013). Manajemen Pemasaran, Jilid 1, Edisi 13, Erlangga

Khuong, Mai Ngoc and Hoang Thi My Duyen, 2017, The Effects of Destination Image, Perceived Value and Service Quality on Tourist Return Intention through Destination Satisfaction, International Journal of Innovation, Management and Technology, Vol. 8, No. 5

Nowacki, Marek , (2010), The Quality of Attractions And The Satisfaction, Benefits And Behavioural Intentions of Visitors:
Verification Of A Model Tourism 20/1 Doi 10.2478/V10106-010-0004-Y

Rambat Lupiyoadi. (2013), Manajemen Pemasaran Jasa (Teori dan Praktek). Edisi Pertama. Penerbit Salemba Empat. Depok.

Romiti, A.and Sarti,D. (2016). Service Quality Experience and Customers' Behavioural Intentions in Active Sport Tourism. Modern Economy, 7,1361-1384

Satyarini, Marsha \& Rahmanita, Myrza \& Setarnawat, Sakchai. (2017). The Influence of Destination Image to Tourist Intention and Decision to Visit Tourism Destination (A Case Study of The Influence of Destination Image on Tourist Intention and Decision to Visit Tourist Destination (A Case Study of Pemuteran Village in Buleleng, Bali, Indonesia). TRJ Tourism Research Journal. 1. 10.30647/trj.v1i1.10.

Shonk, David. (2008). Service Quality, Satisfaction, and Intent to Return in Event Sport Tourism. Journal of Sport Management. $\quad 22 . \quad$ 587-602. 10.1123/jsm.22.5.587.

Siew, Imm, Ng Julie, Anne Lee , Geoffrey N.Soutar , 2007, Tourists' Intention To Visit A Country: The Impact of Cultural Distance, Elsevier, Volume 28, Issue 6, Pages 14971506

Suyan, Shen, Anke Schüttemeyer \& Boris Braun 2009, Visitors' Intention To Visit World Cultural Heritage Sites: An Empirical Study of Suzhou, China, Journal of Travel \& Tourism Marketing, 26:7, 722-734

Tjiptono, F. dan Anastasia D. (2012). Total Quality Manajemen. Edisi Revisi. Andy : Yogyakarta

Uğuz, Elik, Sabriye \& Gacnik, Ales. (2015). Festivals As Cultural Attractions In Tourism: Case of Slovenia. 278-293. 